\title{
Where are you going, where have you been: a recent history of the direct-to-consumer genetic testing market
}

\author{
Pascal Borry • Martina C. Cornel • Heidi C. Howard
}

Received: 18 August 2010 / Accepted: 24 September 2010/Published online: 8 October 2010

(C) The Author(s) 2010. This article is published with open access at Springerlink.com

\begin{abstract}
In recent years, various private companies have been marketing and offering genetic tests directly to consumers. This article reviews the recent history of this commercial phenomenon. In particular, we discuss and describe the following subjects: (1) the factors that allowed for the creation of the direct-to-consumer (DTC) genetic testing (GT) market; (2) information regarding the size and potential success or failure of the DTC GT market; (3) recent changes in the DTC GT market; and (4) the recent events that may have an impact on the regulatory oversight of DTC genetic testing and the future evolution of this market. This review of factors suggests that despite the possibility of a change of business model as well as increased regulation, the commercialization of genetic testing is here to stay. As such it is important to pay close attention not only to the science underlying these tests but also to the ethical, legal, and social issues.
\end{abstract}

\footnotetext{
P. Borry $\cdot$ H. C. Howard

Centre for Biomedical Ethics and Law,

Katholieke Universiteit Leuven,

Kapucijnenvoer 35, P.O. Box 7001, 3000 Leuven, Belgium

P. Borry

Department of Medical Humanities,

VU University Medical Center,

EMGO Institute for Health and Care Research,

Amsterdam, The Netherlands

P. Borry $(\varangle) \cdot$ M. C. Cornel

Department of Clinical Genetics, VU University Medical Center,

EMGO Institute for Health and Care Research,

P.O. Box 7057, 1007 MB Amsterdam, The Netherlands

e-mail: Pascal.Borry@med.kuleuven.be
}

\section{Introduction}

A decade ago, Francis Collins and Victor McKusick predicted that "by the year 2010, it is expected that predictive genetic tests will be available for as many as a dozen common conditions, allowing individuals who wish to know this information to learn their individual susceptibilities and to take steps to reduce those risks for which interventions are or will be available" (Collins and McKusick 2001). They predicted that with the increase of genetic information about common disorders, many primary care clinicians would become "practitioners of genomic medicine, having to explain complex statistical risk information to healthy individuals who are seeking to enhance their chances of staying well." However, with respect to common disorders and susceptibility testing, the anticipated increase of genomic science in the traditional healthcare system has not materialized. In fact, it is private companies who are taking the lead and marketing susceptibility tests directly to consumers. Furthermore, according to some authors, commercial companies may even "come to displace clinicians as the primary providers of genetic information related to health promotion" (Foster and Sharp 2008). Indeed, in the last 3 years, many companies have been advertising and selling genetic tests directly to consumers. In many cases, consumers have been able to purchase genetic testing services without any input from a health care professional.

This article reviews relevant issues surrounding the recent history of the direct-to-consumer (DTC) genetic testing (GT) phenomenon. In particular, we consider the following subjects: (1) the elements that allowed for the creation of the DTC GT market; (2) information regarding the size and potential success or failure of the DTC GT 
market; (3) recent changes in the market; and (4) recent events that could have an impact on the regulatory oversight of these services and the future development of the market.

\section{The rise of DTC companies}

Direct-to-consumer genetic testing is not, strictly speaking, a new phenomenon; by 2003, Williams-Jones reported 12 for-profit companies advertizing on the Internet for susceptibility testing, three of which were also offering the tests DTC (Williams-Jones 2003). Given the lack of high-profile popularity of these services for the following 4 to 5 years, however, this review is focused on the commercial activities since 2007-2008, which roughly marks a period during which a large number of companies entered the DTC genetic testing market. Presently, according to an overview by the Genetics and Public Policy Center, approximately 30 companies are currently offering genetic testing services directly to consumers (Genetics and Public Policy Center 2009). The types of tests being offered are extremely varied and include traditional monogenic testing as well as tests that offer information regarding health enhancement (nutrigenomics, dermatogenetics), drug response (pharmacogenomics), and susceptibility for common complex disorders (cardiovascular diseases, depression, osteoporosis, type 2 diabetes...). Furthermore, some companies are offering genetic profiles or "genome scans" which involve testing hundreds of thousands of single nucleotide polymorphisms. Based on these results, consumers are then given their personal risks of developing various disorders compared to the average risk in a population.

In order to understand how the phenomenon of DTC genetic testing may evolve in the future, it is important to better understand how this field came into being. As Hedgecoe and Martin (2003) describe it, understanding the formation, mobilization, and shape of the created vision is central to the analysis of an emerging biotechnology. The articulation of a vision constitutes a particular class of expectations that legitimizes a new technology, helps to mobilize funds, allows decision-making, and reduces the uncertainty inherent in technological developments (Hedgecoe and Martin 2003). The progress in genetic sequencing and genotyping technologies has changed DNA analysis from an intensive, burdensome, and expensive process to a relatively cheap and easy one. Elaborating on the results of genomewide association studies, there is a drive to develop valid disease risk predictions and consequently offer tailor-made disease management and treatment. Based on this scientific progress and the relatively small presence of genetics in the primary healthcare setting, private companies moved ahead and made it possible for consumers to order genetic testing directly via the Internet.

The principle notions used in the marketing of DTC genetic tests are autonomy, empowerment, prevention, convenience, and privacy. One of the main aspects outlined in the vision of these companies is that individuals want to play a greater role in the process of obtaining, storing and protecting their genetic information. They promote the notion that avoiding the traditional encounter with a healthcare professional will result in a better guarantee of privacy, at least with respect to insurance companies and employers. Moreover, DTC genetic tests allow consumers to collect their own saliva samples (from which DNA is then extracted) from the comfort of their own home. For some tests, the companies argue that it eliminates the hassle of scheduling an appointment with a physician and it eliminates an appointment fee that would otherwise be billed in addition to the laboratory fee (Berg and FryerEdwards 2008). Companies also allege that this model will allow for the increased access of genetic technologies for all consumers. Furthermore, companies advance that this provides "the foundation for truly personalized medicine in which individuals are empowered not only with selfknowledge of their genetic risk, but also with the ability to take informed actions to prevent disease and preserve health" (Ledley 2002).

"No one is going to invest in a start-up company, or a large-scale scientific endeavor, such as the Human Genome Project, unless they genuinely believe it has the potential to yield significant returns in a defined timescale" (Nightingale and Martin 2004). The same is true for direct-to-consumer genetic testing. The emergence of this field has rested heavily on the creation of high expectations in order to get access to researchers, venture capital, and customers. Now that companies are operating, it is a question of convincing the public that they need to buy these tests. Among many others, the following aspects will be important determinants of consumer acceptance: the price, their belief, and understanding of marketing messages and whether this commercial product responds to their expectations and needs.

\section{Success and failure of the DTC market}

Presently, little is known about the actual number of genetic tests sold by DTC genetic testing companies. A few studies have shown that only a relatively small percentage of the US population is aware of the availability of direct-toconsumer genetic tests and only a fraction of these have purchased such tests (Goddard et al. 2007, 2009; Kolor et al. 2009). In a recent study by Wright and Gregory-Jones, the authors attempted to estimate the size of the DTC whole 
genome scan market using the Internet traffic on three companies' websites as a proxy for their commercial activity (Wright and Gregory-Jones 2010). Despite the limited scope of interpretation and generalization allowed by this method, their conclusion that the demand for whole genome scans is fairly small is congruent with the previously mentioned studies. That being said, they still estimated the market for the three most prominent genome profiling companies (23andme, deCODE and Navigenics) to be around US \$10-20 million in 2009. This implies that these companies certainly know how to attract certain consumers; however, in order to be a sustainable business, they need be able to do more than simply attract a bunch of enthusiastic early adopters of new technologies. The announcement in November 2009 by the biotech company deCODE Genetics, (which markets the DTC genetic service called deCODEme) that it had filed a voluntary petition for relief under Chapter 11 of the USA Bankruptcy Code raised the question whether other companies offering DTC genomics services would also follow suit (Hayden 2009). An analysis of DTC genetic testing companies' activities in this field shows that various genetic tests that were marketed are no longer available for purchase from certain companies. For example, the following tests (from certain companies) are no longer available for purchase: tests that predicted AIDS progression based on an analysis of CCR5Delta 32 and CCR2-64I genes (www.hivgene.com, www. hivmirror.com); nutrigenomic tests (www.mycellf.com, www.genecare.co.za, www.integrativegenomics.com); risk assessment tests of various common disorders such as cardiovascular disease, osteoporosis, immune system defects, Alzheimer Disease (www.genovations.com, www. smartgenetics.com, www.qtrait.com); tests for addiction (www.docblum.com); pharmacogenomic tests (www.signaturegenetics.com); carrier testing for disorders such as cystic fibrosis (www.udlgenetics.com). Meanwhile, additional companies retracted their product from the market temporarily for unknown reasons (www.genotrim.com, www.psynomics. com), and it is unclear whether they will be available again. Other initiatives, such as the free "comprehensive genetic test" (www.geneview.com), also disappeared. Since these companies have, for the most part, left the market in silence, it is difficult to understand exactly their reasons for doing so. One may suggest that the consequences of the global financial crisis (initiated in 2007-2008) may have contributed to the downfall of some of these companies (i.e., failure to find enough paying customers). That being said, it seems that various companies also struggled with intellectual property protection (Bandelt et al. 2008; Knowledge 2009) and the legal requirement that a physician should be involved in the ordering of genetic tests (Wadman 2008) (which is the case in some states in the USA such as Connecticut and Michigan; The Genetics and Public Policy Center 2010). Furthermore, companies testing only a few mutations (with each mutation corresponding to one trait) may have had difficulties competing with companies like 23andme, which offer full genome scans (Hayden 2008). Other companies deliberately chose to focus on ancestry testing and have avoided making statements about health risks (Altman 2009). Such companies offering DNA tests for genealogical information now exist in abundance (Bandelt et al. 2008).

\section{Evolution of the DTC GT market}

As with any new market, commercial success for DTC GT companies will depend greatly on the public demand for these services. This consumer demand, in turn, will depend on many factors, including consumers' desire or need to obtain genetic testing services outside of the traditional health care system. With this in mind, the DTC model of genetic testing may have underestimated the consumer's attachment to their physician. A report by the investment bank Burril \& Company (San Francisco) revealed that physicians remain the most likely source to which individuals will turn for health and genetic information. (Burril \& Company/Change Wave Research 2008) A few studies also showed that two thirds of consumers who ordered genetic tests directly to consumer shared their test results with their healthcare professional or were planning to do so (Kolor et al. 2009; McGuire et al. 2009). In general, the DTC model creates concerns for potential consumers regarding credibility of tests, security of DNA use, privacy of genetic risk information, and lack of confidence in non face-to-face genetic counseling (Wilde et al. 2010; People Science and Policy Ltd 2002). With this in mind, it is not surprising that various companies have opted for DTC advertising instead of DTC sales of their services. They have combined the DTC advertising along with the involvement of regular healthcare professionals who then order the test for their patients. Depending on the test, some companies require an order from a physician (e.g., www.hairdx.com) or an oncologist (e.g., www.collabrx. com). The company Counsyl, (www.counsyl.com) which offers pre-conceptional carrier testing, changed its policy since its launch in February 2010. At the time, Counsyl underlined the possibility of ordering the test directly from the company: "You can order the test directly from our website to receive your kit immediately. Everyone has a prescription: the American College of Medical Genetics (ACMG) recommends that adults of reproductive age be offered carrier testing for cystic fibrosis and spinal muscular atrophy, two of the many conditions assayed by the Universal Genetic Test. Alternatively, you may get the test through your doctor." (https://www.counsyl.com/learn/easy/ accessed 04/05/2010) Since May 2010, however, testing 
from Counsyl can only be requested through a physician; therefore, consumers first need to find a physician that offers the test. The company also sends the results directly to the physician for interpretation, thereby, technically no longer selling tests directly to consumers (https://www. counsyl.com/learn/easy/ accessed 06/06/2010). The offer through physicians may eliminate some of the concerns that arose about information provision but does not remove the issue of the appropriateness of the test provided. In this context it becomes important whether physicians will take a role of gatekeeper for tests that may prove to be inappropriate. Furthermore, one must question whether physicians are appropriately educated to take on this role, and we must guard against physicians simply becoming tools for commercial genetic testing companies to look more legitimate and sell more tests.

Moreover, it is no surprise that some companies have tried to get financial support from the healthcare system (Brdicka and Macek 2009) or insurance companies, and are attempting to gain the support of physicians working within the health care system. DTC GT companies are also developing tools to store genomic information in electronic health files as well as to enable physicians to access the genomic information of their consenting patients (Vanier 2009). Moreover, companies are also trying to establish collaborations with healthcare institutions and academic researchers. Ironically, the highly hyped DTC offer of genetic testing could vanish in this way, as it may merge into the regular healthcare system (while still, marketing tests directly to consumers and to physicians).

\section{Regulatory evolutions}

Next to the volume of sales, the future of the DTC market will be highly influenced by regulations meant to govern the sales and marketing of DTC genetic testing services. Discussions about this phenomenon regularly reveal the deficiencies in the current regulatory frameworks (Kaye 2008). As many companies operate from the USA, it will be crucial to see how this country will develop regulatory oversight in the future. After the partnership announcement between Pathway Genomics and the drugstore chain Walgreens to sell DTC genetic tests, the US Food and Drug Administration (FDA) decided to investigate the activities of DTC companies more carefully (Allison 2010; Genetics and Public Policy Center 2010). Between May and July 2010, the FDA sent letters to various companies telling them that they were unable to "identify any Food and Drug Administration clearance or approval number" (Food and Drug Administration 2010b). Moreover, in mid-July 2010, the FDA held a meeting to discuss the oversight of laboratory developed tests (LDTs) (Food and Drug Administration 2010a). The issue of (lack of) oversight of LDTs or "home brews" is closely related to that of DTC GT since many of the tests offered by DTC GT companies could be considered LDTs. Until now, the FDA did not require that most LDTs be reviewed for clinical validity (the exception being those genetic tests that produce a result "for the purpose of diagnosing, treating, or preventing disease" (e.g., breast cancer and prostate cancer)) (Genetics and Public Policy Center 2010). Immediately after this FDA meeting, the Committee on Energy and Commerce held a public hearing on July 222010 (Committe on Energy and Commerce 2010), during which the Report Direct-toconsumer genetic tests. Misleading test results are further complicated by deceptive marketing and other questionable practices by the US Government Accountability Office was presented (United States Government Accountability Office 2010). Although no concrete regulatory changes have taken place since these events, it has to be expected that regulatory oversight will increase in the near future.

In Europe, the Human Genetics Commission of the UK presented in August its "framework of principles" on DTC genetic testing (Human Genetics Commission 2010). These principles were developed by a working group including representatives from the DTC genetic testing industry, clinical, and molecular geneticists, genetic counselors, experts in regulation, and those with experience in offering support to individuals with genetic conditions. The principles are mainly aimed at self-regulation of the DTC genetic testing market by promoting standards in the provision of genetic tests amongst commercial providers at an international level. The principles have been designed with the will to protect the interests of consumers and to allow the industry to grow. However, the principles have been criticized for being "weak and meaningless" by GeneWatch UK (GeneWatch 2010) and an editorial in the Lancet calls the guidelines insufficient and questions their practical value (The Lancet 2010). Furthermore, the Professional and Public Policy Committee of the European Society of Human Genetics had criticized the consultation document for focusing "too much on the requirements the test providers should fulfill while paying too little attention to the quality of the genetic tests that are being sold" and remained "concerned about the quality of the tests provided" and believed "that the clinical validity (and not only the analytical validity) of genetic tests should be proven before one can even begin to consider selling such tests directly to consumers" (Professional and Public Policy Committee of the European Society of Human Genetics 2009). With this in mind, the European Society of Human Genetics endorsed in June 2010 a statement in which it recommended to ensure, among other issues, the quality of the testing services, the provision of pretest information and genetic counseling, a face to face consultation, and oversight of this industry. (European Society of Human Genetics 2010) As may be the 
case in the USA, stronger regulatory oversight may be forthcoming in Europe considering that the European Commission is in a process of revising the Directive 98/ 79/EC of the European Parliament and of the Council of 27 October 1998 on In Vitro Diagnostic Medical Devices. A specific question addressed is the "need to create additional requirements or restrictions for direct-toconsumer genetic tests in order to ensure a better health protection" (European Commission. Health and Consumers Directorate-General. Consumer Affairs. Cosmetics and Medical Devices 2010). Further implementation of the Additional Protocol concerning Genetic Testing for Health Purposes to the Convention on Human rights and Biomedicine may lead to the legal obligation to ensure scientific validity and clinical utility of the tests offered as well as the need for individualized and face-to-face medical supervision (Borry 2008). Moreover, some individual European countries, such as Germany, Switzerland, and France have legislations that prohibit direct-toconsumer genetic testing.

\section{Conclusion}

As it stands now, the many companies that have left the direct-to-consumer genetic testing market are an indication that hyped products and unrealistic expectations may not create the expected return on investment. Further regulatory oversight may well make it impossible for DTC genetic testing companies to operate using the same business model in the future. Although regulation may restrict or ban DTC genetic testing hereafter, these actions will not necessarily address important underlying issues within the DTC GT phenomenon, namely the questions of how and when to translate genomic discoveries into healthcare. Furthermore, important ethical and social issues regarding DTC GT including, among others, concerns regarding privacy, confidentiality, the use of consumers' samples in research activities, the testing of minors, and the potential overconsumption of limited healthcare resources (Borry et al. 2009, 2010; Howard and Borry 2008; Howard et al. 2010) must also be addressed. The fact that some DTC GT companies stopped their online delivery of genetic tests and yet continued the DTC marketing and are now working through healthcare professionals strengthens the debate on the integration of genomics knowledge into healthcare. The healthcare system will have to be prepared for the implementation of useful testing as well as to resist collaboration with commercial companies that offer tests without clinical utility. Initiatives such as the Evaluation of Genomic Applications in Practice and Prevention, Gene Dossiers (UK National Health System), and Gene Cards (EuroGentest) which synthesizes available data on the clinical validity and utility of specific genetic tests will be crucial in this regard.

Acknowledgements $\mathrm{PB}$ is funded by the Research Fund Flanders (FWO); HCH is funded by the European Commission FP7 Marie Curie initiative. MC is principal investigator in the Centre for Society and Genomics, which is funded by the Netherlands Genomics Initiative.

Conflict of interest No competing interests

Open Access This article is distributed under the terms of the Creative Commons Attribution Noncommercial License which permits any noncommercial use, distribution, and reproduction in any medium, provided the original author(s) and source are credited.

\section{References}

Allison M (2010) Genetic testing clamp down. Nat Biotechnol 28:633 Altman RB (2009) Direct-to-Consumer genetic testing: failure is not an option. Clin Pharmacol Ther 86:15-17

Bandelt HJ, Yao YG, Richards MB, Salas A (2008) The brave new era of human genetic testing. Bioessays 30:1246-1251

Berg C, Fryer-Edwards K (2008) The ethical challenges of direct-toconsumer genetic testing. J Bus Ethics 77:17-31

Borry P (2008) Europe to ban direct-to-consumer genetic tests? Nat Biotechnol 26:736-737

Borry P, Howard HC, Senecal K, Avard D (2009) Direct-to-consumer genome scanning services. Also for children? Nat Rev Genet 10:8

Borry P, Howard HC, Senecal K, Avard D (2010) Health-related directto-consumer genetic testing: a review of companies' policies with regard to genetic testing in minors. Fam Cancer 9:51-59

Brdicka R, Macek M Jr (2009) Direct-to-consumer genetic testing also in our country. Cas Lék Cesk 148:56-58

Collins FS, McKusick VA (2001) Implications of the human genome project for medical science. JAMA 285:540-544

Committe on Energy and Commerce (2010) Hearing on "Direct-ToConsumer Genetic Testing and the Consequences to the Public Health".http://energycommerce.house.gov/index.php?option= com_content\&view=article\&id=2083: hearing-on-direct-toconsumer-genetic-testing-and-the-consequences-to-the-publichealth\&catid $=133$ : subcommittee-on-oversight-and-investigations \&Itemid $=73$ (Accessed 5 August 2010)

Burril \& Company/Change Wave Research (2008) Personalized medicine and wellness survey. Executive Summary., http:// www.burrillandco.com/content/CWSurvey_61708.pdf (Accessed 21 September 2010)

Food and Drug Administration (2010a) FDA/CDRH public meeting: oversight of Laboratory Developed Tests (LDTs), Date July 19-20, 2010. www.fda.gov/MedicalDevices/NewsEvents/Workshops Conferences/ucm212830.htm\#webcast (Accessed 5 August 2010)

Food and Drug Administration (2010b) Letters to manufacturers concerning genetic tests. www.fda.gov/MedicalDevices/Products andMedicalProcedures/InVitroDiagnostics/ucm219582.htm (Accessed 9 August 2010)

European Commission. Health and Consumers Directorate-General. Consumer Affairs. Cosmetics and Medical Devices (2010) Revision of directive 98/79/EC of the European Parliament and of the Council of 27 October 1998 on In Vitro Diagnostic Medical Devices. Public Consultation.http://ec.europa.eu/consumers/sectors/medicaldevices/files/recast_docs_2008/public_consultation_ivd_final_en. pdf (Accessed 12 August 2010) 
European Society of Human Genetics (2010) Statement of the ESHG on direct-to-consumer genetic testing for health-related purposes. Eur J Hum Genet advance online publication, 25 August 2010; doi:10.1038/ejhg.2010.129

Foster MW, Sharp RR (2008) Out of sequence: how consumer genomics could displace clinical genetics. Nat Rev Genet 9:419

GeneWatch (2010) GeneWatch slams voluntary gene test guidelines.http:// www.genewatch.org/article.shtml?als $\% 5 \mathrm{Bcid} \% 5 \mathrm{D}=565806 \& \mathrm{als} \%$ 5Bitemid\%5D=566543 (Accessed 12 August 2010)

Goddard KAB, Szegda KL, Ottman D, Bradley L, Moore C, Khoury MJ (2007) Awareness and use of direct-to-consumer nutrigenomic tests, United States, 2006. Genet Med 9:510-517

Goddard KAB, Duquette D, Zlot A, Johnson J, Annis-Emeott A, Lee PW, Bland MP, Edwards KL, Oehlke K, Giles RT et al (2009) Public awareness and use of direct-to-consumer genetic tests: results from three state population-based surveys, 2006. Am J Public Health 99:442-445

Hayden EC (2008) Alzheimer's tests under fire. Nature 455:1155

Hayden EC (2009) Icelandic genomics firm goes bankrupt. Nature 462:401

Hedgecoe A, Martin P (2003) The drugs don't work: expectations and the shaping of pharmacogenetics. Soc Stud Sci 33:327-364

Howard H, Borry P (2008) Direct-to-consumer genetic testing: more questions than benefits? Personalised Med 5:317-320

Howard HC, Knoppers BM, Borry P (2010) Blurring lines. The research activities of direct-to-consumer genetic testing companies raise questions about consumers as research subjects. EMBO Rep 11:579-582

Professional and Public Policy Committee of the European Society of Human Genetics (2009) Letter to the human genetics commission., https://www.eshg.org/fileadmin/www.eshg.org/documents/ PPPC-ESHG-DTC-06122009.pdf (Accessed 21 September 2010)

Human Genetics Commission (2010) a common framework of principles for direct-to-consumer genetic testing services.http://www.hgc.gov. $\mathrm{uk} /$ Client/document.asp?DocId $=280 \&$ CAtegoryId $=10$ (Accessed 11 August 2010)

Kaye J (2008) The regulation of direct-to-consumer genetic tests. Hum Mol Genet 17:R180-R183

Knowledge Wharton (2009) Can anyone make sense-or money - out of personal DNA testing?, http://knowledge.wharton.upenn.edu/ article.cfm?articleid=1757 (Accessed 21 September 2010)
Kolor K, Liu TB, St Pierre J, Khoury MJ (2009) Health care provider and consumer awareness, perceptions, and use of direct-toconsumer personal genomic tests, United States, 2008. Genet Med 11:595

Lancet T (2010) New guidelines for genetic tests are welcome but insufficient. Lancet 376:488

Ledley F (2002) A consumer charter for genomic services. Nat Biotechnol 20:767

McGuire A, Diaz CM, Wang T, Hilsenbeck S (2009) Social networkers' attitudes toward direct-to-consumer personal genome testing. Am J Bioeth 9:3-10

Nightingale P, Martin P (2004) The myth of the biotech revolution. Trends Biotechnol 22:564-569

People Science and Policy Ltd (2002) The supply of genetic tests direct to the public: supporting the public consultation., http:// www.hgc.gov.uk/UploadDocs/DocPub/Document/evidence focusgroup.pdf (Accessed 21 September 2010)

Genetics and Public Policy Center (2009) http://www.dnapolicy.org/ resources/DTCcompanieslist.pdf (Accessed 21 September 2010)

Genetics and Public Policy Center (2010) FDA regulation of genetic tests.www.dnapolicy.org/images/issuebriefpdfs/FDA Regulation_of_Genetic_Test_Issue_Brief.pdf (Accessed 9 August 2010)

United States Government Accountability Office (2010) Direct-toconsumer genetic tests misleading test results are further complicated by deceptive marketing and other questionable practices. http://energycommerce.house.gov/documents/20100722/Kutz. Testimony.07.22.2010.pdf (Accessed 10 August 2010)

Vanier V (2009) Navigenics launches new service and physician portal., http://blog.navigenics.com/articles/navigenics_launches_new_ service_and physician_portal/ (Accessed 21 September 2010)

Wadman M (2008) Gene-testing firms face legal battle. Nature 453:1148-1149

Wilde A, Meiser B, Mitchell PB, Schofield PR (2010) Public interest in predictive genetic testing, including direct-to-consumer testing, for susceptibility to major depression: preliminary findings. Eur J Hum Genet 18:47-51

Williams-Jones B (2003) Where there's a web, there's a way: commercial genetic testing and the internet. Community Genet 6:46-57

Wright CF, Gregory-Jones S (2010) Size of the direct-to-consumer genomic testing market. Genet Med 12:594 